\title{
Experimental Methods on Glass Fiber Reinforced Self Compaction Concrete
}

\author{
A. Deepak Raj, M. Mergin Benize, J. Esther Daisy, M. Sri Nikhil \\ Assistant Professor, Department of Civil Engineering, M.N.M Jain Engineering College, Chennai, Tamilnadu, India. \\ P.G Student, Department of Civil Engineering, M.N.M Jain Engineering College, Chennai, Tamilnadu, India. \\ P.G Student, Department of Civil Engineering, M.N.M Jain Engineering College, Chennai, Tamilnadu, India. \\ P.G Student, Department of Civil Engineering, M.N.M Jain Engineering College, Chennai, Tamilnadu, India.
}

\begin{abstract}
Self Compacting Concrete (SCC) is able to flow under its own weight and completely fill the formwork, even in the presence of congested reinforcement, without any compaction, while maintaining homogeneity of the concrete. Compaction is difficult to be done in conditions where there are dense reinforcement and large casting area. Usage of SCC will overcome the difficult casting conditions and reduce manpower required. Addition of fibers will enhance the tensile and ductile behavior of concrete with brittle nature. SCC was added with relatively short, discrete, and discontinuous glass fibers to produce Glass Fiber Reinforced Self Compacting Concrete (GFRSCC). The purpose of this study is to investigate the workability and mechanical properties of plain SCC and GFRSCC. The laboratory testing included slump flow test, L-Box test, sieve segregation resistance test, density test, ultrasonic pulse velocity (UPV) test, compressive strength test, splitting tensile strength test, and flexural strength test. The dosage of super plasticizer required increased as fiber content increased. There has been a lack of studies for productivity improvement in the construction industry. A review of literature was done where an inventory of productivity related factors were found and interpolated. A survey of construction practitioners was conducted to rank and determine the degree of influence of various factors on construction productivity. We have selected the major factors such as Material, Labor and accessed it both quantitatively and qualitatively for a real time construction project. The results enhanced profit and productivity.
\end{abstract}

\section{Introduction}

SCC can be considered as a concrete with high flow ability that can be placed and compacted under its own weight without any external vibration, assuring complete filling of formworks and also the complete covering of the reinforcing bars even when the space between the reinforcements is very narrow. SCC is characterized by high flow ability in its fresh state and increased strength in its hardened state because of a compact matrix structure. SCC has many advantages that include faster construction, better surface finishes, easier placing, reduction in noise levels and improved durability.

The term Fiber Reinforced Concrete (FRC) can be defined as a concrete structure having randomly oriented and dispersed fibers. Fibers can be defined as small wire-like reinforcements which are made of either steel or polymers having high ductility. The fibers are produced in a wide range of sizes and shapes, stiff or flexible etc. Addition of fibers into concrete improves the overall ductility of the concrete imparting toughness, greater tensile strength, and resistance to fatigue, impact, blast loading and abrasion. Fibers are added not only to improve the ductility of concrete but also, more importantly to control the cracking, by the bridging of the fibers across the cracks, which delay the propagation and widening of localized cracks. The use of glass fibers in SCC might bring together the advantages of both fibers and SCC. Glass Fiber Reinforced Self-Compacting Concrete (GFRSCC) combines the advantages of SCC in its fresh state and that of fibers in its hardened state. Because of the superior performance of SCC in its fresh state, addition of fibers will lead to a more uniform dispersion of fibers which is very critical for the performance of any fiber reinforced composite. Also the compactness of SCC matrix due to higher amount of finer particles may improve the interface zone properties and consequently the fiber-matrix bond leading to enhanced post-cracking toughness and energy absorption capacity

\begin{tabular}{|l|l|l|}
\hline S. No & Properties & Values \\
\hline 1 & Specific gravity of C.A & 2.71 \\
\hline 2 & Bulk Density in loose state & $1346.7 \mathrm{~kg} / \mathrm{m}^{3}$ \\
\hline 3 & Bulk Density in compacted state & $1480.07 \mathrm{~kg} / \mathrm{m}^{3}$ \\
\hline 4 & Crushing strength & $19.93 \%$ \\
\hline 5 & Impact strength & $8.97 \%$ \\
\hline
\end{tabular}




\section{Self Compaction Concrete}

The main characteristics of SCC are the properties in the fresh state. The mix design is focused on the ability to flow under its own weight without vibration, the ability to flow through heavily congested reinforcement under its own weight and the ability to retain homogeneity without segregation. The workability of SCC is higher than very high degree of workability mentioned in IS 456:2000.The three basic requirements for a concrete to be considered as self-compactable according to EFNARC (European Federation of Specialist Construction Chemicals and Concrete Systems) are:

Filling Ability

It is the ability of SCC to flow into and fill completely all the spaces within the formwork under its own weight without any external energy without leaving voids. It also shows how fast the SCC flows under its own weight without losing its stability.

Passing Ability It is the ability of SCC to flow through and around restricted spaces such as spaces between steel reinforcing bars without segregation or blocking. Also the concrete must adhere completely to the reinforcing bars. Segregation Resistance

The ability of SCC is to remain homogenous in composition during transport and placing without any signs of bleeding. This is achieved mainly by the high viscosity of the cement paste. Also it is a fact that the viscosity of $\mathrm{SCC}$ is highest among other concrete due to its lowest water powder ratio.

\section{Material Properties}

Table - 1 Properties of Coarse Aggregates

\begin{tabular}{|l|l|l|}
\hline S. No & Properties & Values \\
\hline 1 & Specific gravity & 2.45 \\
\hline 2 & Bulk Density in loose state & $1294.87 \mathrm{Kg} / \mathrm{m}^{3}$ \\
\hline 3 & Bulk Density in compacted state & $1442.16 \mathrm{~kg} / \mathrm{m}^{3}$ \\
\hline 4 & Fineness Modules & 3.2 \\
\hline 5 & Zone & II \\
\hline
\end{tabular}

Table - 2 Properties of Fine Aggregates

\begin{tabular}{|l|l|l|}
\hline S. No & Properties & Values \\
\hline 1 & Specific gravity & 3.15 \\
\hline 2 & Consistency & $31 \%$ \\
\hline 3 & Intial Setting Time & 40 Minutes \\
\hline 4 & Final Setting Time & 300 Minutes \\
\hline
\end{tabular}

Table - 3 Chemical Composition of Flyash

\begin{tabular}{|l|l|l|}
\hline S. No & Chemical Composition & Percentage \\
\hline 1 & $\begin{array}{l}\text { Silicon dioxide (SiO2) + aluminum oxide (Al2O3) } \\
+ \text { iron oxide (Fe2O3), min, } \%\end{array}$ & 70 \\
\hline 2 & Sulfur trioxide (SO3), max, \% & 5 \\
\hline 3 & Moisture content, max, $\%$ & 3 \\
\hline
\end{tabular}

Table - 4 Properties of S-Glass Fibre

\begin{tabular}{|l|l|l|}
\hline S. No & Properties & Values \\
\hline 1 & Tensile Strength & $4890 \mathrm{Mpa}$ \\
\hline 2 & Compressive Strength & $1600 \mathrm{Mpa}$ \\
\hline 3 & Density & $2.46 \mathrm{~g} / \mathrm{cm}^{3}$ \\
\hline 4 & Thermal Expansion & $2.9 \mu \mathrm{m} /{ }^{\circ} \mathrm{c}$ \\
\hline 5 & Softening Temperature & $1056^{\circ} \mathrm{C}$ \\
\hline
\end{tabular}

\section{Codal Reccomendations For Scc}

\section{A. Slump flow test}

The slump-flow Test using the traditional slump cone is the most common field test. It is simple and most widely used to assess the horizontal flow and the flow rate of SCC in the absence of obstructions. The test, which was developed in Japan, was originally used to measure underwater concrete and has also been used to 
measure highly flowable concretes. Also T500, which is the time required for the concrete to spread to a diameter of $500 \mathrm{~mm}$ is also measured to assess the flow ability. The higher the slump flow value, the greater its ability to fill formwork under its own weight. A value of at least $650 \mathrm{~mm}$ is required for SCC under EFNARC guidelines. There is no generally accepted advice on what are reasonable tolerances about a specified value, though $\pm 50 \mathrm{~mm}$, as with the related flow table test, might be appropriate. The T500 time is a secondary indication of flow. A lower time indicates greater flow ability and vice versa. In case of severe segregation most of the coarse aggregate will remain in the centre of the pool of concrete and mortar and cement paste at the concrete periphery. In case of minor segregation a border of mortar without coarse aggregate can occur at the edge of the pool of concrete. If none of these phenomena appear it is no assurance that segregation will not occur since this is a time related aspect that can occur after a longer period.

\section{B. V-Funnel Test}

The described V-funnel test is used to determine the filling ability of the concrete with a maximum aggregate size of $20 \mathrm{~mm}$. The test was developed in Japan and used by Ozawa et al. The equipment consists of a $\mathrm{V}$-shaped funnel as shown Fig 3.1. An alternative type of $\mathrm{V}$-funnel, the $\mathrm{O}$ funnel, with a circular section is also used in Japan. The funnel is filled with concrete and the time taken for it to flow through the apparatus is measured. After this the funnel can be refilled with concrete and left for 5 minutes to settle. If the concrete shows segregation then the flow time will increase significantly. This test measures the ease of flow of the concrete; shorter flow times indicate greater flow ability. For SCC a flow time of 10 seconds is considered appropriate under EFNARC guidelines. The inverted cone shape restricts flow, and prolonged flow times may give some indication of the susceptibility of the mix to blocking. After 5 minutes of settling, segregation of concrete will show a less continuous flow with an increase in flow time.

\section{L-Box Test}

The test assesses the flow of the concrete, and also the extent to which it is subject to blocking by reinforcement. The apparatus consists of a rectangular-section box in the shape of an $\mathrm{L}$, with a vertical and horizontal section, separated by a moveable gate, in front of which vertical lengths of reinforcement bar are fitted. Fig 3.2 shows the L-Box test apparatus. The vertical section is filled with concrete, and then the gate lifted to let the concrete flow into the horizontal section. When the flow has stopped, the height of the concrete at the end of the horizontal section is expressed as a proportion of that remaining in the vertical section. It indicates the slope of the concrete when at rest. This is an indication passing ability, or the degree to which the passage of concrete through the bars is restricted. The sections of bar can be of different diameters and spaced at different intervals: in accordance with normal reinforcement considerations, three times the maximum aggregate size might be appropriate. The bars can principally be set at any spacing to impose a more or less severe test of the passing ability of the concrete. Obvious blocking of coarse aggregate behind the reinforcing bars can be detected visually.

Table - 6. Recommended Limits for Different Properties of SCC

\begin{tabular}{|l|l|l|l|}
\hline S. No & Properties & Range & Values \\
\hline 1 & Slump Flow Diameter & $500-700 \mathrm{~mm}$ & Filling Ability \\
\hline 2 & T $50 \mathrm{~cm}$ & $2-5 \mathrm{sec}$ & Filling Ability \\
\hline 3 & V - funnel & $8-12 \mathrm{sec}$ & Passing Ability \\
\hline 4 & V - funnel - T5 min & $11-15 \mathrm{sec}$ & Segregation Resistance \\
\hline 5 & L - Box H2/H1 & $\mathbf{2 0 . 8}$ & Passing Ability \\
\hline
\end{tabular}

IV. Mix Proportion Of Scc, Gfrsce \& Test Results Table - 7. Mix Proportion of SCC

\begin{tabular}{|l|l|l|}
\hline S. No & Materials & Quantity \\
\hline 1 & Water & $180 \mathrm{Kg} / \mathrm{m}^{3}$ \\
\hline 2 & Cement & $350 \mathrm{Kg} / \mathrm{m} 3$ \\
\hline 3 & Flyash & $150 \mathrm{~kg} / \mathrm{m}^{3}$ \\
\hline 4 & Fine Aggregate & $850 \mathrm{Kg} / \mathrm{m}^{3}$ \\
\hline 5 & Coarse Aggregate & $920 \mathrm{Kg} / \mathrm{m}^{3}$ \\
\hline 6 & Super Plasticizer & $1.00 \%$ of cementitious materials \\
\hline
\end{tabular}

*-About $30 \%$ of cement was replaced by Fly Ash. 
Since there is no proper design procedure is available for SCM, the final mix proportions were designed based on the trial and error method in which various proportions of fly ash and superplasticizer have been tried to arrive at the mix giving the appropriate workability which meets the self compacting standards. The different lengths of fibers $(1.2 \mathrm{~mm}, 1.8 \mathrm{~mm}$ and $2.4 \mathrm{~mm})$ were added to the self compacting mix with different percentages $(0 \%, 0.25 \%, 0.5 \%, 0.75 \%$ and $1 \%)$

\begin{tabular}{|l|l|l|}
\hline $\begin{array}{l}\text { S. } \\
\text { No }\end{array}$ & Designation & Mix Proportion \\
\hline 1 & SCC 1 & S0.25\%G1* \\
\hline 2 & SCC 2 & S0.50\%G1 \\
\hline 3 & SCC 3 & S0.75\%G1 \\
\hline 4 & SCC 4 & S1 $\%$ G1 \\
\hline 5 & SCC 5 & S0.25\%G2 \\
\hline 6 & SCC 6 & S0.50\%G2 \\
\hline 7 & SCC 7 & S0.75\%G 2 \\
\hline 8 & SCC 8 & S1 $\%$ G2 \\
\hline 9 & SCC 9 & S0.25\%G3 \\
\hline 10 & SCC 10 & S0.50\%G3 \\
\hline 11 & SCC 11 & S0.75\%G3 \\
\hline 12 & SCC 12 & S1 $\% G 3$ \\
\hline
\end{tabular}

S0.25\% G1- $0.25 \%$ of S-glass fiber content with respect to the binder ratio of length G1. (G1-1.2mm; G2$1.8 \mathrm{~mm} ; \mathrm{G} 3-2.4 \mathrm{~mm})$

Table-8. Mix Proportion of GFRSCC

\begin{tabular}{|c|c|c|c|c|c|c|}
\hline S. No & Designation & $\begin{array}{l}\text { Slump flow } \\
(\mathbf{m m})\end{array}$ & T 500( mm) & $\begin{array}{l}\text { V - Funnel } \\
\text { (Sec) }\end{array}$ & $\begin{array}{l}\text { V - Funnel at } T \\
5 \mathrm{~min}(\mathrm{Sec})\end{array}$ & $\begin{array}{l}\text { L- Box } \\
(\text { h2/h1) }\end{array}$ \\
\hline 1 & SCC & 720 & 2 & 7 & 9 & 0.82 \\
\hline 2 & SCC 1 & 705 & 2.5 & 8 & 10 & 0.89 \\
\hline 3 & SCC 2 & 695 & 3 & 9 & 11.5 & 0.93 \\
\hline 4 & SCC 3 & 670 & 4.1 & 9.5 & 13 & 0.99 \\
\hline 5 & SCC 4 & 650 & 5 & 10 & 15 & 1.1 \\
\hline 6 & SCC 5 & 701 & 2.5 & 7.5 & 10.5 & 0.9 \\
\hline 7 & SCC 6 & 690 & 3 & 8.5 & 12 & 0.95 \\
\hline 8 & SCC 7 & 665 & 4 & 9 & 13 & 1.0 \\
\hline 9 & SCC 8 & 645 & 5 & 10.5 & 15.5 & 1.2 \\
\hline 10 & SCC 9 & 690 & 3 & 8 & 11 & 0.91 \\
\hline 11 & SCC 10 & 680 & 4.5 & 8.9 & 12.5 & 0.96 \\
\hline 12 & SCC 11 & 660 & 5 & 9.6 & 14 & 1.1 \\
\hline 13 & SCC12 & 635 & 6 & 11 & 16 & 1.4 \\
\hline
\end{tabular}

\section{Conclusion}

With reference to the obtained test results we conclude that the addition of S-glass fibers does not affect the filling ability, passing ability and segregation resistance of the SCC. The workability test is conducted on 12 trial mixes of GFRSCC by varying the length of the glass and the amount of glass fibers added to the mix. We can observe from the result that the flow ability of GFRSCC is directly proportional to its length and quantity added (i.e.) the result comes under the range of recommended values when the quantity and length of the glass fiber added is maximum. $1 \%$ of S- glass fiber in all sizes (G1, G2, and G3) is more flow able than $0.25 \%$ of S-glass fiber in all sizes. We can notice that the $1 \%$ of $2.4 \mathrm{~mm}(\mathrm{G} 3)$ size glass fiber (i.e.) SCC12 results are well within the ranges of the recommended values by EFNARC.

\section{References}

[1] Barluenga G, Hernandez-Olivares F (2007) „Cracking Control of Concretes Modified with Short Ar-Glass Fibers at Early Age. Experimental results on standard concrete and scc"e, Vol .37, pp 1624-1638.

[2] Barluenga Gonzalo (2009) „Fibre-Matrix Interaction At Early Ages Of Concrete With Short Fibres“, Vol 4, Pp 1922-1948

[3] Kannan S.U, Selvamony C., Ravikumar M.S. and Basil Gnanappa S (2010), „Investigations and study on the effect of ar glass polymer fibres in self-compacting self-curing concrete", vol. 5, pp 41-45. 
[4] Libre N.A, Mehdipour I, A. Alinejad, N. Nouri (2008), „Rheological Properties Of Glass Fiber Reinforced Highly Flowable Cement Paste", The 3rd Acf International Conference-Acf/Vca, Pp 53-58.

[5] Rathish Kumar P and K. Srikanth (2008), Mechanical Characteristics Of Fiber Reinforced Self Compacting Mortars"e, Vol 9, Pp 647-657.

[6] SeshadriSekhar.T, Dr. P. Sravana and Dr. SrinivasaRao P (2007),„Non-Destructive Testing: Pulse Velocity Behaviour Of Glass Fibre Self Compacting Concrete After Exposure To Elevated Temperature", Vol 1, Pp 57-61.

[7] Suresh Babu T, SeshagiriRao M.V and Rama Seshu D (2007), Mechanical Properties and Stress- Strain Behaviour of SelfCompacting Concrete With And Without Glass Fibres"e, Vol. 9, No. 5, pp 457-472.

[8] Shetty M.S (2006), ,Concrete Technology - Theory And Practicee, Sixth Edition S.Chand and Company Limited.

[9] K. H. Khayat, Y. Roussel, "Testing And Performance Of Fiber-Reinforced, Self- Consolidating Concrete”, July 2000, Volume 33, Issue 6, Pp 391-397.

[10] Yasser Sheriff, "Structural Performance Of Self-Consolidating Concrete Used In Reinforced Concrete Beams", May 2012, Volume 16, Issue 4, Pp 618-626.

[11] M. Sonebi, P. J. M. Bartos, ” Filling Ability And Plastic Settlement Of Self-Compacting Concrete”, September-October 2002, Volume 35, Issue 8, Pp 462-469.

[12] V. Boel, K. Audenaert, G. De Schutter, "Gas Permeability And Capillary Porosity Of Self-Compacting Concrete", August 2008, Volume 41, Issue 7, Pp 1283-1290.

[13] S. Grunewald, F. Laranjeira, J. Walraven, A. Aguado, C. Molins, "Improved Tensile Performance With Fiber Reinforced SelfCompacting Concrete", Rilem State Of The Art Reports Volume 2, 2012, Pp 51-58.

[14] "Final Report Of Rilem Tc 205-Dsc: Durability Of Self-Compacting Concrete”, March 2008, Volume 41, Issue 2, Pp 225-233.

[15] PrakashNanthagopalan, Manu Santhanam, "An Empirical Approach For The Optimisation Of Aggregate Combinations For SelfCompacting Concrete", August 2012, Volume 45, Issue 8, Pp 1167-1179.

[16] “Final Report Of Rilem Tc 188-Csc „Casting Of Self Compacting Concrete”, December 2006, Volume 39, Issue 10, Pp 937-954.

[17] P. Ramanathan, I. Baskar, P. Muthupriya, R. Venkatasubramani, "Performance Of Self-Compacting Concrete Containing Different Mineral Admixtures", March 2013, Volume 17, Issue 2, Pp 465-472.

[18] Malek Mohammad Ranjbar, S. YasinMousavi, "Strength And Durability Assessment Of Self-Compacted Lightweight Concrete Containing Expanded Polystyrene", November 2013.

[19] Specification And Guidelines For Self-Compacting Concrete, February 2002, EFNARC.

[20] The European Guidelines for Self Compacting Concrete Specification, Production and Use, May 2005.

[21] IS 383: 1970, „Specification For Coarse and Fine Aggrgates from Natural Sources For Concrete (Second Revision) ${ }^{\text {‘e }}$, Bureau of Indian standards, New Delhi, India.

[22] IS: 456-2000, Plain And Reinforced Concrete - Code of Practice.

[23] IS: 2386-1963, Methods Of Test For Aggregates For Concrete Bureau of Indian standards, New Delhi, India.

[24] IS 12269:1987, Specification For 53 Grade Ordinary Portland Cement", Bureau Of Indians Standards, New Delhi, India.

[25] IS 456: 2000, „Code Practice For Plain And Cement Concrete (Fourth Revision) ${ }^{e c}$, Bureau Of Indian Standards, New Delhi, India. 